Article

\title{
Study of Sputtered ITO Films on Flexible Invar Metal Foils for Curved Perovskite Solar Cells
}

\author{
Hae-Jun Seok and Han-Ki Kim * \\ School of Advanced Materials Science and Engineering, Sungkyunkwan University, Suwon, Gyeonggi-do 16419, \\ Korea; hj.seok@skku.edu \\ * Correspondence: hankikim@skku.edu; Tel.: +82-31-290-7391
}

Received: 3 December 2018; Accepted: 22 January 2019; Published: 24 January 2019

\begin{abstract}
We have studied characteristics of tin-doped indium oxide (ITO) films sputtered on flexible invar metal foil covered with an insulating $\mathrm{SiO}_{2}$ layer at room temperature to use as transparent electrodes coated substrates for curved perovskite solar cells. Sheet resistance, optical transmittance, surface morphology, and microstructure of the ITO films on $\mathrm{SiO}_{2}$ /invar substrate are investigated as a function of the thickness from 50 to $200 \mathrm{~nm}$. The optimized ITO film exhibits a low sheet resistance of $50.21 \mathrm{Ohm} /$ square and high optical transmittance of up to $94.31 \%$ even though it is prepared at room temperature. In particular, high reflectance of invar metal substrate could enhance the power conversion efficiency of curved perovskite solar cell fabricated on the $\mathrm{ITO} / \mathrm{SiO}_{2} /$ invar substrate. In addition, critical bending radius of the $150 \mathrm{~nm}$-thick ITO film is determined by lab-designed outer and inner bending tests to show feasibility as flexible electrode. Furthermore, dynamic fatigue test is carried out to show flexibility of the ITO film on invar metal substrate. This suggests that the $\mathrm{ITO} / \mathrm{SiO}_{2} /$ invar substrate can be applied as flexible electrodes and substrates for curved perovskite solar cells.
\end{abstract}

Keywords: indium tin oxide (ITO); invar metal substrate; curved perovskite solar cells; flexibility; reflectance; electrode

\section{Introduction}

Methylammonium lead tri-iodide $\left(\mathrm{MAPbI}_{3}\right)$ perovskite solar cells (PSCs) have emerged as next generation photovoltaics following Si-based photovoltaics and organic photovoltaics due to their high power conversion efficiencies larger than $20 \%$ and solution-based simple fabrication process [1-5]. In particular, planar heterojunction type flexible perovskite solar cells have been extensively investigated because planar architecture is easily fabricated on flexible substrate at low temperature. However, most flexible PSCs fabricated on plastic substrate exhibited limit in reliability and stability due to high water vapor transmission rate (WVTR) values of conventional plastic substrates [6-11]. To solve the problem of typical plastic substrates, flexible metal foils with smooth surface have emerged as promising flexible substrate for flexible photovoltaics and flexible organic light emitting diodes (OLEDs) [12-16]. Especially, metal foil substrates have many advantages over polymer substrates, such as enhanced chemical stability and lower thermal expansion coefficients. Furthermore, a high temperature process is possible due to the higher thermal stability of metal foil compared to that of polymers, and a passivation layer is not required to prevent water vapor and oxygen migrating through the substrate [17-20]. On the other hand, impurities from the metal substrate and surface roughness are significant issues impeding their electronic applications. In particular, device performance may deteriorate due to out-diffusion of detrimental elements from the metal foil, such as Fe atoms, and electrical short circuits (i.e., direct contact of the anode and cathode electrode in solar cell devices) due to severe surface roughness [21-23]. Lee et al. suggested that invar metal foil is a 
promising flexible substrate material for flexible OLEDs [12]. Im et al. also reported that flexible PSCs fabricated on metal foil had a power conversion efficiency of 15\% [24]. Typically, most of PSCs have been fabricated on physical vapor deposited Sn-doped $\mathrm{In}_{2} \mathrm{O}_{3}$ (ITO) electrode [25-27]. DC sputtered amorphous ITO films with fairly high sheet resistances (30-100 Ohm/square) and average optical transmittances of $80-85 \%$ have been widely employed as flexible electrodes for flexible optoelectronic devices. Although the potential of invar metal foil as flexible substrate for flexible optoelectronic devices has been well-known, detailed investigation of Sn-doped $\operatorname{In}_{2} \mathrm{O}_{3}$ (ITO) films on invar metal foil is still necessary. Recently, we reported high quality flexible ITO electrodes with a low sheet resistance of $15.75 \mathrm{Ohm} /$ square, high optical transmittance of $85.88 \%$, and outstanding flexibility grown by ion plating for flexible PSCs [28]. Because most research of PSCs has mainly been focused on active materials and interface buffer layers, investigation of flexible ITO films for curved or flexible PSCs is still lacking.

In this study, we investigated the electrical, optical, morphological and mechanical properties of DC sputtered ITO films on invar foil substrate as a function of ITO film thickness to show feasibility of invar metal substrate for curved perovskite solar cells. In particular, outer and inner bending tests were carried out to determine critical bending radius of ITO film on the invar metal substrate. In addition, resistance change of the ITO films during repeated bending cycles at a fixed bending radius of $15 \mathrm{~mm}$ was measured to show stable mechanical flexibility. The possible growth mechanism of ITO films on the $\mathrm{SiO}_{2}$ coated invar metal substrate was suggested to correlate film thickness and characteristics of ITO films. In addition, we report a preliminary study of a perovskite solar cell fabricated on invar substrate.

\section{Materials and Methods}

The $120 \mu \mathrm{m}$ thick invar metal foil ( $36 \% \mathrm{Ni}-64 \% \mathrm{Fe}$ ) was employed as flexible substrate to deposit flexible ITO anode for curved perovskite solar cells. Before sputtering of ITO films, the $2 \mu \mathrm{m}$ thick $\mathrm{SiO}_{2}$ insulating layer was deposited on invar substrate using plasma enhanced chemical vapor deposition. Then, transparent ITO film with a thickness in the range 50-200 nm was sputtered on the $\mathrm{SiO}_{2}$ coated invar substrate using a four-inch ITO target (Dasom RMS) at room temperature. During ITO sputtering process, DC power of $100 \mathrm{~W}$, Ar flow rate of $20 \mathrm{sccm}$, and a working pressure of $3 \mathrm{mTorr}$ was kept constant. Figure 1a shows the fabrication process of flexible ITO films on invar substrate. The ITO coated invar foil could be used as flexible substrate in curved perovskite solar cells as illustrated in Figure 1b. Due to opacity of invar substrate, the light was absorbed through the transparent top cathode unlike typical glass-based perovskite solar cells. The thickness of ITO films was measured using a profilometer (NanoMap LS, aep Technology, Newyork, NY, USA). Through Hall measurements (HMS-4000AM, Ecopia, Anyang-si, Korea) and a UV-visible spectrometer (UV 540, Unicam, Hachioji, Japan) analysis, the electrical and optical properties of the flexible ITO films were examined as a function of thickness. The morphology and microstructure of ITO film on $\mathrm{SiO}_{2}$ coated invar substrate according to the increasing thickness was examined by field emission scanning electron microscope (FESEM: JSM-7600F, JEOL, Akishima, Japan) and X-ray diffraction (XRD, D8 ADVANCE, Bruker Corporation, Billerica, MA, USA). The mechanical flexibility of the ITO films on $\mathrm{SiO}_{2}$ coated invar substrate was investigated by using a lab-designed outer/inner bending test machine (JUNIL TECH Co., DaeGu-Si, Korea). The resistance changes of the ITO films during outer and inner bending of substrate were measured with decreasing bending radius in order to determine critical bending radius. By pressing the clamped samples, we can control the bending radius. In outer and inner bending tests, both clamps moved simultaneously to specific position to make specific bending radius. Then, dynamic outer/inner fatigue tests were performed at a fixed bending radius of $15 \mathrm{~mm}$ for 10,000 cycles. 
(a)

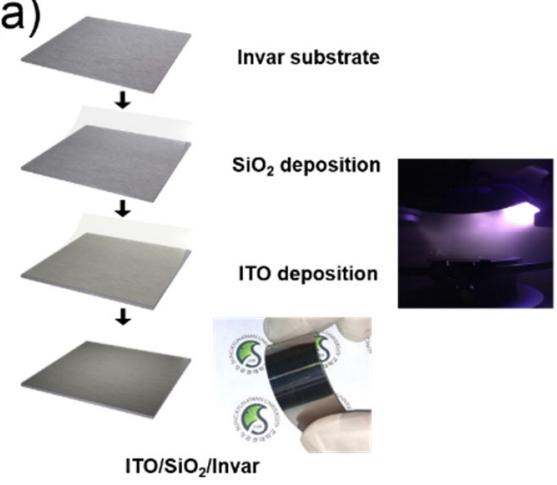

(b)

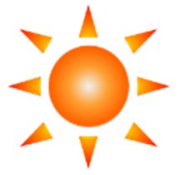

Solar incident light

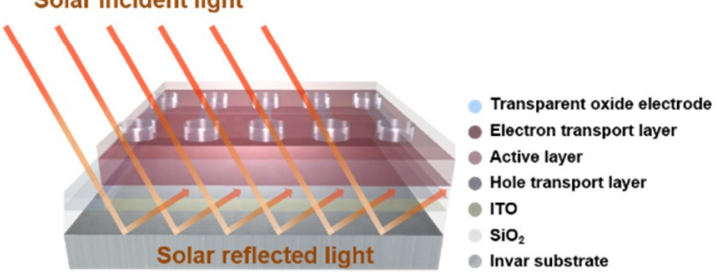

Figure 1. (a) Schematic fabrication process of flexible ITO films on $\mathrm{SiO}_{2}$ coated invar metal substrate using typical DC magnetron sputtering at room temperature. The images show ITO sputtering process and curved invar substrate with ITO electrodes. (b) Device structure of curved perovskite solar cells with transparent $\mathrm{InSnO}$ anode and $\mathrm{InZnSnO}$ top cathode.

\section{Results and Discussion}

Figure 2a,b shows the Hall measurement results of ITO films sputtered on $\mathrm{SiO}_{2}$ coated invar substrate and glass substrate in same chamber with increasing film thicness. With increasing ITO film thickness, the sheet resistance gradually decreased. Table 1 summarized sheet resistance of ITO films on the $\mathrm{SiO}_{2}$ coated invar and glass substrate, respectively. Regardless of substrates, the DC sputtered ITO films showed a similar sheet resistance at a same film thickness. Because the insulating $\mathrm{SiO}_{2}$ layer completely covered the invar substrate, the ITO film on $\mathrm{SiO}_{2} /$ invar substrate showed a similar sheet resistance to the ITO films on glass substrates. At a thickness of $200 \mathrm{~nm}$, the ITO films on $\mathrm{SiO}_{2} / \mathrm{invar}$ and glass substrate showed an identical sheet resistance of 44.57 and $44.52 \mathrm{Ohm} /$ square and resistivity of $8.91 \times 10^{-4}$ and $8.90 \times 10^{-4} \mathrm{Ohm} \times \mathrm{cm}$, respectively.

(a)

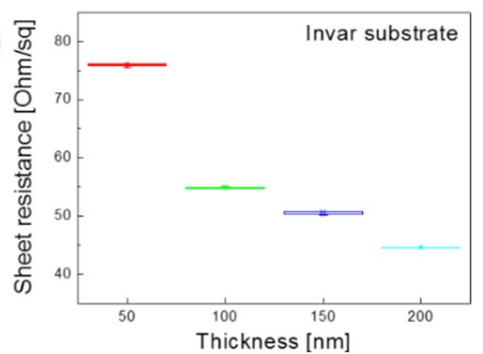

(c)

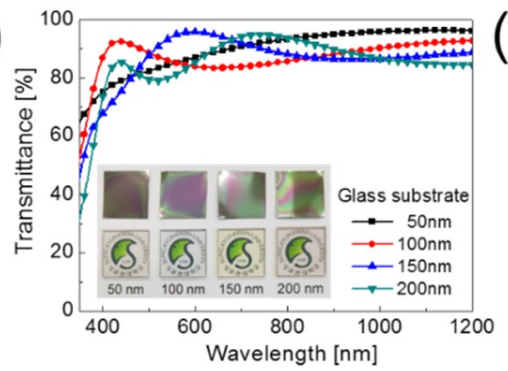

(b)

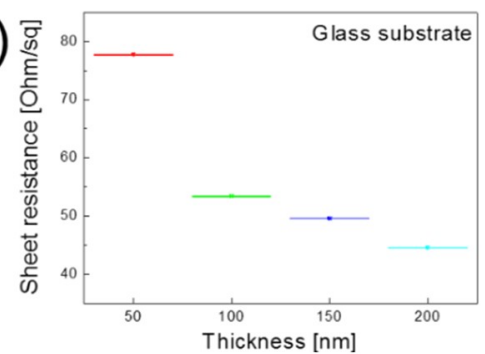

(d)

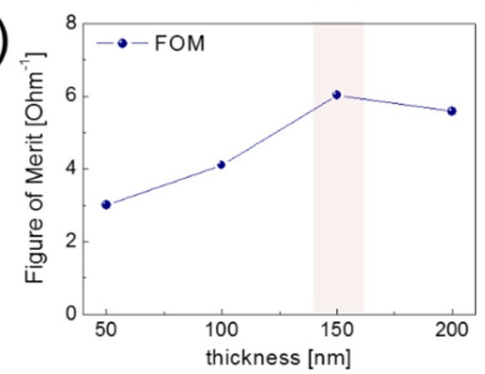

Figure 2. Hall measurement results of ITO films on (a) $\mathrm{SiO}_{2}$ coated invar and (b) glass substrates prepared at room temperature with increasing thickness (50, 100, 150, $200 \mathrm{~nm}$ ). (c) Optical transmittance of ITO films on glass substrates. Inset: pictures of ITO films deposited on invar substrates (upper figure) and on glass substrates (lower figure). (d) Figure of merit $\left(\mathrm{FoM}=T^{10} / R_{\mathrm{sh}}\right.$ ) of ITO film on $\mathrm{SiO}_{2} /$ invar substrates as a function of thickness. 
Table 1. Sheet resistance of ITO films on the $\mathrm{SiO}_{2} /$ invar and glass substrates with increasing ITO thickness.

\begin{tabular}{ccccc}
\hline \multirow{2}{*}{ Substrate } & \multicolumn{4}{c}{ Sheet Resistance $(\mathbf{R s})(\mathbf{O h m} / \mathbf{s q u a r e})$} \\
\cline { 2 - 5 } & $\mathbf{5 0} \mathbf{~ n m}$ & $\mathbf{1 0 0} \mathbf{~} \mathbf{m}$ & $\mathbf{1 5 0} \mathbf{~ n m}$ & $\mathbf{2 0 0} \mathbf{~ n m}$ \\
\hline Invar & 75.54 & 54.74 & 50.21 & 44.57 \\
Glass & 77.64 & 53.30 & 49.51 & 44.52 \\
\hline
\end{tabular}

Figure 2c shows optical transmittance of ITO films on the glass substrate. Due to opacity of invar substrate, the optical transmittance of the ITO films was measured from the ITO film sputtered on glass substrate at same sputtering conditions with invar substrates. All ITO films show a high optical transmittance in the visible region regardless film thickness. With increasing ITO film thickness, oscillations in the optical transmittance was observed due to light interference phenomena $[29,30]$. Table 2 showed the average transmittance $(400-800 \mathrm{~nm})$ of ITO films on glass substrate as a function of thickness. At the $150 \mathrm{~nm}$-thick ITO film, the average transmittance had the highest value of $88.73 \%$. To determine optimum ITO thickness, we compared figure of merit ( $\left.\mathrm{FoM}=T^{10} / R_{\mathrm{sh}}\right)$ values, which were calculated from the average optical transmittance $(T)$ and the sheet resistance $\left(R_{\mathrm{sh}}\right)$, as shown in Figure 2d [31]. Because the active layer of the PSCs absorbs visible light (400-800 nm), the FoM values are calculated using the average optical transmittance $(400-800 \mathrm{~nm})$. In addition, the voltage loss of the PSCs is influenced by the sheet resistance of the transparent electrode. Therefore, the exciton generation and voltage loss of the PSC are closely related to the FoM value, which is the quality of the transparent electrode. For those reasons, the optimum ITO thickness on the invar substrate was determined by the FoM value. Based on FoM calculation, we found that the $150 \mathrm{~nm}$-thick ITO film had the highest FoM value of $6.02 \mathrm{Ohm}^{-1}$. In invar-based perovskite solar cells, optical reflectance on the surface of invar substrate is very important because photon penetrating perovskite active layer could be reflected from the surface of invar substrate as illustrated in Figure $1 \mathrm{~b}$.

Table 2. Average transmittance of ITO films on the glass substrate with increasing ITO thickness.

\begin{tabular}{|c|c|c|c|c|}
\hline \multirow{2}{*}{ Substrate } & \multicolumn{4}{|c|}{ Average Transmittance $(400-800 \mathrm{~nm})(\%)$} \\
\hline & $50 \mathrm{~nm}$ & $100 \mathrm{~nm}$ & $150 \mathrm{~nm}$ & $200 \mathrm{~nm}$ \\
\hline Glass & 86.23 & 86.12 & 88.73 & 87.01 \\
\hline
\end{tabular}

Figure 3a shows optical reflectance of $\mathrm{ITO} / \mathrm{SiO}_{2} /$ invar samples with different ITO thickness. Due to high reflectance of invar substrate, all samples showed high reflectance regardless of ITO thickness. Optical reflectance of the $\mathrm{ITO} / \mathrm{SiO}_{2} /$ invar samples are similar to $\mathrm{SiO}_{2} /$ invar substrate. Figure $3 b$ exhibited XRD plots of ITO films on $\mathrm{SiO}_{2} /$ invar substrate with increasing thickness. The diffraction peaks appear at $2 \theta=30.28^{\circ}, 35.18^{\circ}, 37.06^{\circ}, 50.57^{\circ}$, and $60.15^{\circ}$, corresponding to the (222), (400), (411), (440), and (622) orientations. The several diffraction peaks demonstrate that the DC sputtered ITO films have a typical bixbyite structure even though they were prepared at room temperature. The intensity of XRD peaks increased due to well-developed polycrystalline structure and increase in sub-grain sizes. In addition, ITO film showed (222) preferred orientation with increasing film thickness. Kim et al. also reported that DC sputtered ITO films had a (222) preferred orientation with increasing film thickness [32]. Although we employed invar metal substrate, the ITO films ware directly sputtered on $\mathrm{SiO}_{2}$ insulating layer, the microstructure of ITO film on $\mathrm{SiO}_{2}$ /invar substrate is similar to the ITO films on glass or fused silica $\left(\mathrm{SiO}_{2}\right)$ substrate. 
(a)

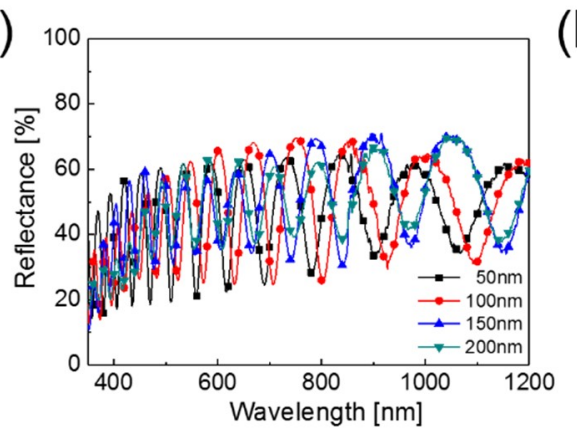

(b)

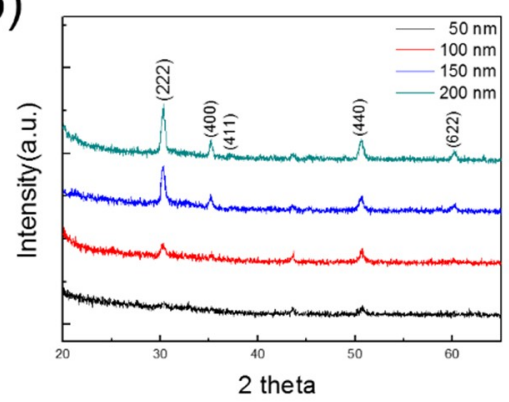

Figure 3. (a) Reflectance ITO films sputtered on $\mathrm{SiO}_{2}$ coated invar substrate with increasing film thickness. (b) XRD plots of the ITO films sputtered on $\mathrm{SiO}_{2}$ coated invar substrate at room temperature as a function of film thickness.

Figure 4 shows surface FESEM images of DC sputtered ITO films on $\mathrm{SiO}_{2} /$ invar substrate with increasing film thickness. At a thickness of $50 \mathrm{~nm}$ in Figure 4a, the ITO film showed garlic-flower like surface morphology due to amorphous sub-grain as expected from XRD plot. However, surface FESEM image of the ITO film with a thickness of $100 \mathrm{~nm}$ showed sub-grains consisting of micro-crystals as shown in Figure $4 \mathrm{~b}$. Further increase in thickness led to (222) preferred oriented surface morphology of ITO films as expected from XRD plots. As shown in Figure 4c, the 150-nm thick ITO films consisted of (222) oriented grains with a triangular-shape. The triangular-shaped ITO grains indicate that DC sputtered ITO films on $\mathrm{SiO}_{2}$ /invar substrate have a (222) preferred orientation. However, the 200-nm thick ITO films exhibit triangular-shaped (222), square-shaped (400), and rectangular-shaped (440) grains as shown in Figure $4 \mathrm{~d}$ [27]. As expected from the XRD plots, these grain shapes indicate that the 200-nm thick ITO film consists of primarily (222), (400), and (440) grains. Due to the difference in sub-grain height, we can easily distinguish the sub-grain direction of DC-grown ITO films on $\mathrm{SiO}_{2}$ /invar substrate. As we reported in previous work [27], the surface of sputtered ITO films experienced severe ion bombardments from energetic particles in high density plasma. This bombardment resulted in re-sputtering of the specific plane of the ITO films. Due to different surface energy of special crystalline ITO planes, the re-sputtering phenomenon resulted in specific surface morphology of the ITO film depending on its preferred orientation.
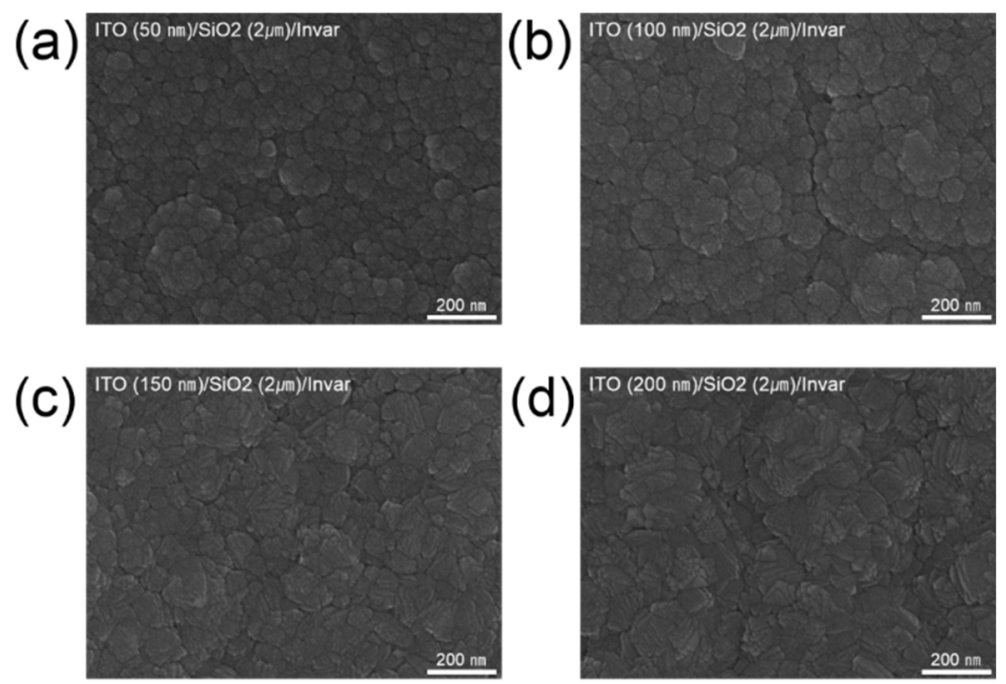

Figure 4. Surface FESEM images of DC sputtered ITO films on $\mathrm{SiO}_{2}$ /invar substrates; (a) $50 \mathrm{~nm}$, (b) $100 \mathrm{~nm},(\mathbf{c}) 150 \mathrm{~nm}$, and (d) $200 \mathrm{~nm}$.

To determine the critical outer and inner bending radii of the ITO film on $\mathrm{SiO}_{2}$ /invar substrate, the resistance change $(\Delta R)$ of the ITO film was measured in-situ by reducing the bending radius, 
as shown in Figure 5a. Here, the critical bending radius $\left(r_{\mathrm{c}}\right)$ is defined as the bending radius where the resistance abruptly increases due to the formation and propagation of cracks. The outer/inner bending test results showed that the 150 nm-thick ITO film on $\mathrm{SiO}_{2} /$ invar substrate had a constant resistance until the bending radii became $11 \mathrm{~mm}$ (outer bending) or $11 \mathrm{~mm}$ (inner bending), as shown in Figure 5a. Beyond this critical bending radius, the resistance of the film rapidly increased due to crack formation and physical separation of the ITO film. Due to thick $2 \mu \mathrm{m}$ of $\mathrm{SiO}_{2}$ on invar substrate, cracking in the ITO $(150 \mathrm{~nm}) / \mathrm{SiO}_{2}$ multilayer led to increase in the resistance. Figure $5 \mathrm{~b}$ shows the dynamic bending test results of the ITO $(150 \mathrm{~nm}) / \mathrm{SiO}_{2} /$ invar substrate with an increasing number of bending cycles at a fixed bending radius of $15 \mathrm{~mm}$, which is larger than critical bending radius. The picture in upper panels in Figure $5 b$ shows the dynamic outer and inner bending fatigue test steps with increasing bending cycles, up to 10,000 cycles.

(a)
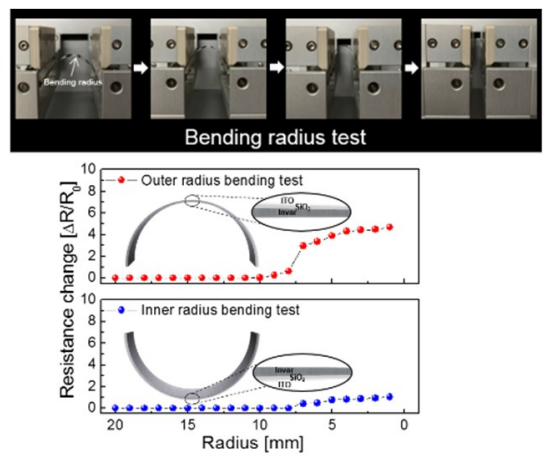

(b)
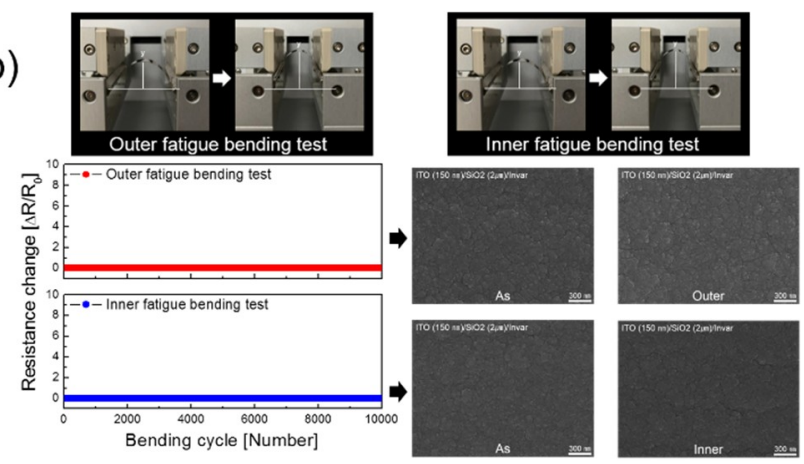

Figure 5. (a) Upper panels show pictures of the outer bending test steps with decreasing bending radius. Results of the outer and inner bending test with decreasing bending radius of $150 \mathrm{~nm}$ thick ITO films on $\mathrm{SiO}_{2}$ /invar substrate. Insets show the schematics of curved sample experiencing tensile and compressive stress. (b) Results of the outer and inner dynamic bending fatigue tests at a fixed bending radius of $15 \mathrm{~mm}$ for the $150 \mathrm{~nm}$ thick ITO films on $\mathrm{SiO}_{2} /$ invar substrate. The right side shows FESEM images of the ITO film before and after dynamic fatigue test after 10,000 cycles.

Figure $5 b$ shows both dynamic outer and inner bending fatigue tests of the ITO (150 nm)/ $\mathrm{SiO}_{2} /$ invar substrate; no change in the resistance $(\Delta R)$ is observed, even after 10,000 bending cycles, demonstrating the outstanding flexibility and mechanical reliability of the ITO $(150 \mathrm{~nm}) / \mathrm{SiO}_{2} /$ invar substrate. Even after 10,000 outer and inner bending cycles, the surface of the ITO film showed an identical morphology to the as-deposited ITO film. The crystalline and featureless surface morphology of the sample is typical of a crystalline ITO film prepared at room temperature. Considering the application of curvature of perovskite solar cells, the outstanding flexibility and small critical bending radius of ITO film on $\mathrm{SiO}_{2} /$ invar substrate is acceptable in fabrication of curved perovskite solar cells.

Based on FoM value and bending test results, curved PSC was fabricated on a 150 nm-thick ITO film. Figure 6a depicts current density-voltage $(J-V)$ curve of the PSC on the ITO $(150 \mathrm{~nm}) / \mathrm{SiO}_{2} /$ invar substrate. Figure $6 \mathrm{~b}$ shows schematic representation of the PSC fabrication processes on the ITO $(150 \mathrm{~nm}) / \mathrm{SiO}_{2} /$ invar substrate. The ITO $(150 \mathrm{~nm}) / \mathrm{SiO}_{2} /$ invar substrate underwent UV/ozone treatment for $10 \mathrm{~min}$ before the deposition of a $\mathrm{NiO}$ layer. The desired amount of ethanolic precursor solution containing nickel diacetate tetra-hydrate $\left(\mathrm{Ni}\left(\mathrm{CH}_{3} \mathrm{COO}\right)_{2} \cdot 4 \mathrm{H}_{2} \mathrm{O}\right)$ and $\mathrm{HCI}$ was refluxed at $60{ }^{\circ} \mathrm{C}$ for $2 \mathrm{~h}$. Then, $\mathrm{NiO}$ layer with an average thickness of $12 \mathrm{~nm}$ was fabricated by spin-coating at $3000 \mathrm{rpm}$ for $40 \mathrm{~s}$ in air and the film was annealed at $100{ }^{\circ} \mathrm{C}$ for $30 \mathrm{~min}$. Subsequently, the $\mathrm{MAPbI}_{3}$ was coated onto the $\mathrm{NiO}$ layer by spin-coating at $4000 \mathrm{rpm}$ for $45 \mathrm{~s}$ in air. The electron transport layer $\mathrm{PCBM}$ was grown on the $\mathrm{MAPbI}_{3}$ layer by spin coating at $1000 \mathrm{rpm}$ for $60 \mathrm{~s}$ and the film $100{ }^{\circ} \mathrm{C}$ for $10 \mathrm{~min}$. Finally, $200 \mathrm{~nm}$ IZTO cathodes were formed successively, with the damage-free linear facing target sputtering by using a dumbbell-shaped shadow mask [33]. Table 3 summarizes the key $J-V$ parameters of the curved PSC. The $J-V$ curve of the performing device yields a $V_{\mathrm{OC}}$ of $1.11 \mathrm{~V}$, a $J_{\mathrm{SC}}$ of 
$18.12 \mathrm{~mA} / \mathrm{cm}^{2}$, a fill factor of $47 \%$, and a PCE of $9.70 \%$. Although the PCE of the curved PSC fabricated on ITO/ $\mathrm{SiO}_{2} /$ invar substrate is lower than glass based PSC at this moment, we strongly believe that further optimization of fabrication process could increase PCE of the curved PSC on invar substrate. However, successful operation of curved PSC on invar substrate demonstrates the feasibility of flexible invar substrate for next-generation curved PSCs.
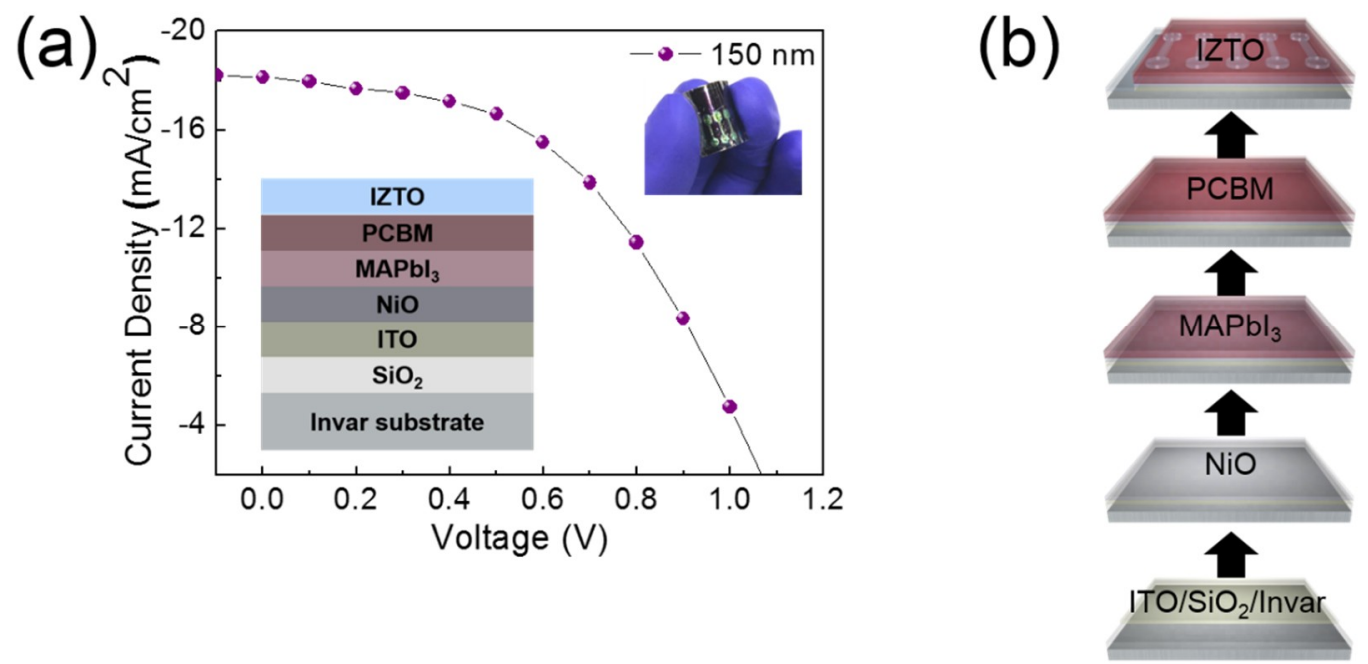

Figure 6. (a) Current density-voltage $(J-V)$ curve of PSC fabrication on the ITO $(150 \mathrm{~nm}) / \mathrm{SiO}_{2} /$ invar substrate (under AM 1.5 solar light). (b) Schematic of a PSC fabrication procedure on the ITO $(150 \mathrm{~nm}) / \mathrm{SiO}_{2} /$ invar substrate.

Table 3. Key parameters of PSC based on ITO $(150 \mathrm{~nm}) / \mathrm{SiO}_{2} /$ invar substrate.

\begin{tabular}{ccccc}
\hline $\begin{array}{c}\text { ITO Thickness } \\
(\mathbf{n m})\end{array}$ & $V_{\text {OC }}(\mathrm{V})$ & $J_{\text {SC }}\left(\mathbf{m A} / \mathbf{c m}^{2}\right)$ & Fill Factor (FF, \%) & $\begin{array}{c}\text { Power Conversion } \\
\text { Efficiency (PCE, \%) }\end{array}$ \\
\hline 150 & 1.11 & 18.12 & 47.0 & 9.70 \\
\hline
\end{tabular}

\section{Conclusions}

The electrical, optical, morphological, and structural properties of DC sputtered ITO films on $\mathrm{SiO}_{2}$ /invar substrates were investigated as a function of ITO thickness. We found that the resistivity and optical transmittance of DC sputtered ITO film on $\mathrm{SiO}_{2}$ /invar is dependent on film thickness. With increasing thickness, the ITO film showed a well-developed crystalline structure with (222) preferred orientation. Based on outer/inner bending test and dynamic fatigue tests, we confirmed the outstanding mechanical flexibility of the $\mathrm{ITO} / \mathrm{SiO}_{2} /$ invar substrate. Based on electrical, optical, and mechanical properties of ITO film on $\mathrm{SiO}_{2}$ /invar substrate, we suggested that the DC sputtered ITO film on $\mathrm{SiO}_{2}$ /invar substrate could substitute ITO film on plastic substrate for curved perovskite solar cells. In addition, a preliminary study of the ITO coated-invar metal foils as a flexible substrate for curved PSCs indicates that invar metal foils are promising flexible substrates to substitute typical flexible polymer substrates for high performance curved PSCs.

Author Contributions: Design of experiment, H.-K.K.; Sputtering and Analysis, H.-J.S.

Funding: This work was supported by the Korea Institute of Energy Technology Evaluation and Planning (KETEP) and the Ministry of Trade, Industry \& Energy (MOTIE) of the Republic of Korea (No. 20163010012200). This study also received partial support from Korea Electric Power Corporation (KEPCO, CX72170049).

Conflicts of Interest: The authors declare no conflict of interest. 


\section{References}

1. Jamal, M.S.; Bashar, M.S.; Mahmud Hasan, A.K.; Almutairi, Z.A.; Alharbi, H.F.; Alharthi, N.H.; Karim, M.R.; Misran, H.; Amin, N.; Sopian, K.B.; et al. Fabrication techniques and morphological analysis of perovskite absorber layer for high-efficiency perovskite solar cell: A review. Renew. Sustain. Energy Rev. 2018, 98, 469-488. [CrossRef]

2. Stranks, S.D.; Snaith, H.J. Metal-halide perovskites for photovoltaic and light-emitting devices. Nat. Nanotechnol. 2015, 10, 391-402. [CrossRef]

3. Li, J.; Jiu, T.; Duan, C.; Wang, Y.; Zhang, H.; Jian, H.; Zhao, Y.; Wang, N.; Huang, C.; Li, Y. Improved electron transport in $\mathrm{MAPbI}_{3}$ perovskite solar cells based on dual doping graphdiyne. Nano Energy 2018, 46, 331-337. [CrossRef]

4. Saliba, M.; Matsui, T.; Seo, J.Y.; Domanski, K.; Correa-Baena, J.P.; Nazeeruddin, M.K.; Zakeeruddin, S.M.; Tress, W.; Abate, A.; Hagfeldt, A.; Grätzel, M. Cesium-containing triple cation perovskite solar cells: Improved stability, reproducibility and high efficiency. Energy Environ. Sci. 2016, 9, 1989-1997. [CrossRef] [PubMed]

5. You, S.; Wang, H.; Bi, S.; Zhou, J.; Qin, L.; Qiu, X.; Zhao, Z.; Xu, Y.; Zhang, Y.; Shi, X.; Zhou, H.; Zhiyong, T. A biopolymer heparin sodium interlayer anchoring $\mathrm{TiO}_{2}$ and $\mathrm{MAPbI}_{3}$ enhances trap passivation and device stability in perovskite solar cells. Adv. Mater. 2018, 30, 1706924. [CrossRef]

6. Bu, T.; Li, J.; Zheng, F.; Chen, W.; Wen, X.; Ku, Z.; Peng, Y.; Zhong, J.; Cheng, Y.B.; Huang, F. Universal passivation strategy to slot-die printed $\mathrm{SnO}_{2}$ for hysteresis-free efficient flexible perovskite solar module. Nat. Commun. 2018, 9, 4609. [CrossRef] [PubMed]

7. Asghar, M.I.; Zhang, J.; Wang, H.; Lund, P.D. Device stability of perovskite solar cells-A review. Renew. Sustain. Energy Rev. 2017, 77, 131-146. [CrossRef]

8. Giacomo, F.D.; Fakharuddin, A.; Jose, R.; Brown, T.M. Progress, challenges and perspectives in flexible perovskite solar cells. Energy Environ. Sci. 2016, 9, 3007-3035. [CrossRef]

9. Shin, S.S.; Yang, W.S.; Noh, J.H.; Suk, J.H.; Jeon, N.J.; Park, J.H.; Kim, J.S.; Seong, W.M.; Seok, S.I. High-performance flexible perovskite solar cells exploiting $\mathrm{Zn}_{2} \mathrm{SnO}_{4}$ prepared in solution below $100{ }^{\circ} \mathrm{C}$. Nat. Commun. 2015, 6, 7410. [CrossRef] [PubMed]

10. Zardetto, V.; Brown, T.M.; Reale, A.; Carlo, A.D. Substrates for flexible electronics: A practical investigation on the electrical, film flexibility, optical temperature, and solvent resistance properties. J. Polym. Sci. Part B Polym. Phys. 2011, 49, 638-648. [CrossRef]

11. Burrows, P.E.; Graff, G.L.; Gross, M.E.; Martin, P.M.; Shi, M.K.; Hall, M.; Mast, E.; Bonham, C.; Bennett, W.; Sullivan, M.B. Ultra barrier flexible substrates for flat panel displays. Displays 2001, 22, 65-69. [CrossRef]

12. Kim, K.; Kim, S.; Jung, G.H.; Lee, I.; Kim, S.; Ham, J.; Dong, W.J.; Hong, K.; Lee, J.L. Extremely flat metal films implemented by surface roughness transfer for flexible electronics. RSC Adv. 2018, 8, 10883-10888. [CrossRef]

13. Luo, Z.; Lu, Y.; Singer, D.W.; Berck, M.E.; Somers, L.A.; Goldsmith, B.R.; Charlie Johnson, A.T. Effect of substrate roughness and feedstock concentration on growth of wafer-scale graphene at atmospheric pressure. Chem. Mater. 2011, 23, 1441-1447. [CrossRef]

14. Calabrese, G.; Pettersen, S.V.; Pfüller, C.; Ramsteiner, M.; Grepstad, J.K.; Brandt, O.; Geelhaar, L.; Fernandez-Garrido, S. Effect of surface roughness, chemical composition, and native oxide crystallinity of the orientation of self-assembled GaN nanowires on Ti foils. Nanotechnology 2017, 28, 425602. [CrossRef]

15. Hong, K.; Yu, H.K.; Lee, I.; Kim, S.; Kim, Y.; Kim, K.; Lee, J.L. Flexible top-emitting organic light emitting diodes with a functional dielectric reflector on a metal foil substrate. RSC Adv. 2018, 8, 26156-26160. [CrossRef]

16. Cheon, J.H.; Choi, J.H.; Hur, J.H.; Jang, J.; Shin, H.S.; Jeong, J.K.; Mo, Y.G.; Chung, H.K. Active-matrix OLED on bendable metal foil. IEEE Trans. Electron Devices 2006, 53, 1273-1276. [CrossRef]

17. Kim, M.; Kim, K.B.; Jeon, C.W.; Lee, D.; Lee, S.N.; Lee, J.M.; Lee, H.C. CIGS solar cell devices on steel substrates coated with Na containing $\mathrm{AIPO}_{4}$. J. Phys. Chem. Solids 2015, 86, 223-228. [CrossRef]

18. Kim, K.B.; Kim, M.; Lee, H.C.; Park, S.W.; Jeon, C.W. Copper indium gallium selenide (CIGS) solar cell devices on steel substrates coated with thick $\mathrm{SiO}_{2}$-based insulating material. Mater. Res. Bull. 2017, 85, 168-175. [CrossRef] 
19. Kim, K.B.; Kim, M.; Baek, J.; Park, Y.J.; Lee, J.R.; Kim, J.S.; Jeon, C. Influence of Cr thin films on the properties of flexible CIGS solar cells on steel substrates. Electron. Mater. Lett. 2014, 10, 247-251. [CrossRef]

20. Si, P.Z.; Choi, C.J. High hardness nanocrystalline invar alloys prepared from Fe-Ni nanoparticles. Metals 2018, 8, 28. [CrossRef]

21. Herz, K.; Eicke, A.; Kessler, F.; Wächter, R.; Powalla, M. Diffusion barrier for CIGS solar cells on metallic substrates. Thin Solid Films 2003, 431-432, 392-397. [CrossRef]

22. Batchelor, W.K.; Repins, I.L.; Schaefer, J.; Beck, M.E. Impact of substrate roughness on $\mathrm{CuIn}_{x} \mathrm{Ga}_{1-x} \mathrm{Se}_{2}$ device properties. Sol. Energy Mater. Sol. Cells 2004, 83, 67-80. [CrossRef]

23. Platzer-Björkman, C.; Jani, S.; Westlinder, J.; Linnarsson, M.K.; Scragg, J.; Edoff, M. Diffusion of Fe and Na in co-evaporated $\mathrm{Cu}(\mathrm{In}, \mathrm{Ga}) \mathrm{Se}_{2}$ devices on steel substrates. Thin Solid Films 2013, 535, 188-192. [CrossRef]

24. Heo, J.H.; Shin, D.H.; Lee, M.L.; Kang, M.G.; Im, S.H. Efficient organic-inorganic hybrid flexible perovskite solar cells prepared by lamination of polytriarylamine $/ \mathrm{CH}_{3} \mathrm{NH}_{3} \mathrm{PbI}_{3}$ /anodized Ti metal substrate and graphene/PDMS transparent electrode substrate. ACS Appl. Mater. Interfaces 2018, 10, 31413-31421. [CrossRef] [PubMed]

25. Suyama, T.; Bae, H.; Setaka, K.; Ogawa, H.; Fukuoka, Y.; Suzuki, H.; Toyoda, H. Quantitative evaluation of high-energy O-ion particle flux in a DC magnetron sputter plasma with an indium-tin-oxide target. J. Phys. D Appl. Phys. 2017, 50, 445201. [CrossRef]

26. Lee, K.Y.; Chen, L.C.; Wu, Y.J. Effect of oblique-angle sputtered ITO electrode in $\mathrm{MAPbI}_{3}$ perovskite solar cell structures. Nanoscale Res. Lett. 2017, 12, 556. [CrossRef]

27. Kim, J.H.; Seong, T.Y.; Ahn, K.J.; Chung, K.B.; Seok, H.J.; Seo, H.J.; Kim, H.K. The effects of film thickness on the electrical, optical, and structural properties of cylindrical, rotating, magnetron-sputtering ITO films. Appl. Surf. Sci. 2018, 440, 1211-1218. [CrossRef]

28. Kim, J.H.; Seok, H.J.; Seo, H.J.; Seong, T.Y.; Heo, J.H.; Lim, S.H.; Ahn, K.J.; Kim, H.K. Flexible ITO films with atomically flat surfaces for high performance flexible perovskite solar cells. Nanoscale 2018, 10, 20587-20598. [CrossRef]

29. Akman, E.; Cerkezoglu, E. Compositional and micro-scratch analyses of laser induced colored surface of titanium. Opt. Lasers Eng. 2016, 84, 37-43. [CrossRef]

30. Pérez del Pino, A.; Fernández-Pradas, J.M.; Serra, P.; Morenza, J.L. Coloring of titanium through laser oxidation: Comparative study with anodizing. Surf. Coat. Technol. 2004, 187, 106-112. [CrossRef]

31. Haacke, G. New figure of merit for transparent conductors. J. Appl. Phys. 1976, 47, 4086-4089. [CrossRef]

32. Kim, H.; Horwitz, J.S.; Kushto, G.; Piqué, A.; Kafafi, Z.H.; Gilmore, C.M.; Chrisey, D.B. Effect of film thickness on the properties of indium tin oxide thin films. J. Appl. Phys. 2000, 88, 6021-6025. [CrossRef]

33. Lee, J.H.; Shin, H.S.; Na, S.I.; Kim, H.K. Transparent and flexible PEDOT:PSS electrodes passivated by thin IZTO film using plasma-damage free linear facing target sputtering for flexible organic solar cells. Sol. Energy Mater. Sol. Cells 2013, 109, 192-198. [CrossRef]

(C) 2019 by the authors. Licensee MDPI, Basel, Switzerland. This article is an open access article distributed under the terms and conditions of the Creative Commons Attribution (CC BY) license (http:/ / creativecommons.org/licenses/by/4.0/). 